\title{
Recent progress on intramolecular charge-transfer compounds as photoelectric active materials
}

\author{
Liang $\mathrm{Xu}^{1^{*}}$ and Qichun Zhang ${ }^{2,3 *}$
}

\begin{abstract}
This article summarized the recent advance on the structural design and synthetic strategies of intramolecular charge-transfer compounds as well as their potential applications in two-photon absorption chromophores, organic photovoltaics and organic light-emitting diodes.
\end{abstract}

Keywords: structural design, intramolecular charge-transfer, photoelectric properties

\section{INTRODUCTION}

Recently, the design and synthesis of novel structures of intramolecular charge-transfer (ICT) compounds have attracted much attention due to their diverse applications in nonlinear optics (NLO) [1], organic photovoltaics [2-8], organic light-emitting diodes (OLEDs) [9], memory devices [10-14], field effect transistors (FETs) [15-16], and so on. ICT compounds normally have coexisted electron donor (D) and electron acceptor (A) moieties, which are connected together through conjugated linkers. The donor and acceptor moieties provide the requisite ground-state charge asymmetry, and after excitation, the charge-transfer states form [17]. Because the charge-transfer states can undergo a geometry relaxation that would affect the excited state properties, ICT compounds normally have many characteristic electronic and optical properties [18].

The great advantages of low-molecular-weight ICT compounds including ready availability, ease of synthesis, and high purity render them attractive candidates for use to investigate the structure-function relationship [19]. These small $\pi$-conjugated molecular systems are generally based on a variety of common chromophores such as anthracene, anthraquinone, pyrene, perylene diimide, fluorene, carbazole, triphenylamine and their derivatives. These $\pi$-conjugated bridges are built mainly through cross-coupling reactions such as Suzuki reaction, Sonogashira reaction, Heck reaction and so on.

In this review, we mainly summarized the structural design strategy for ICT compounds as well as their important structural factors such as the chemical components of D and $\mathrm{A}$, the conjugation length of the $\pi$-bridges, the position of the substitutes, coplanarity and flexibility of the molecular frameworks. Moreover, we also describe the photophysical properties of ICT compounds and the regulation of photo-physical properties through changing structural factors. Finally, we will discuss the structural design strategy for the construction of photoelectric molecular systems.

\section{THE PROPERTIES OF INTRAMOLECULAR CHARGE-TRANSFER}

ICT is an efficient pathway for deactivating the excited states of molecules. Upon photoexcitation of the D fragment in molecules, the local excited (LE) state undergoes ICT from $\mathrm{D}$ to $\mathrm{A}$, accompanying with structural relaxation to form a stabilized dipolar state (namely, charge-transfer state) [18]. For the excited state geometry, several models have been proposed [20]. For example, Grabowski et al. $[21,22]$ proposed a twisted ICT (TICT) state, where a perpendicularly twisted structure between the $\mathrm{D}$ species and the A moieties is suggested. Zachariasse et al. [23] suggested a planar ICT (PICT) model, in which the D and A subgroup would have an overall planar configuration with a substantial electronic coupling. Generally, the TICT

\footnotetext{
${ }^{1}$ Department of Chemistry, College of Science, Shantou University, Shantou 515063, China

${ }^{2}$ School of Materials Science and Engineering, Nanyang Technological University, Singapore 639798, Singapore

${ }^{3}$ Division of Chemistry and Biological Chemistry, School of Physical and Mathematic Sciences, Nanyang Technological University, Singapore 637371, Singapore

*Corresponding authors (emails: qczhang@ntu.edu.sg (Zhang Q); xuliang@stu.edu.cn (Liang X))
} 
model is especially applicable to less extended molecular systems (preferentially with only one aromatic ring) [22]. One of the remarkable features for TICT models is dual fluorescence, mainly originating from both LE and ICT states. In comparison with LE emission, the ICT emission takes place at a lower energy, thus resulting in a red-shifted, broadened peak. While in PICT models, the fluorescence shows a relatively small Stokes shift and elevated intensity due to a shorter D-A bond and a smaller dipole moment in the excited state compared to those of the ground state.

Besides dual fluorescence, ICT molecules have many other important photo-physical properties. Firstly, they often have an intense charge-transfer (CT) band in the absorption spectrum because the excitation energy is relatively small [19]. Meanwhile, by extending the $\pi$-conjugation within an ICT molecule, significant red-shift of the absorption band could be obtained. Secondly, ICT molecules exhibit relatively weak fluorescence intensity. Thirdly, ICT molecules show solvent-dependent behaviors. With the increased solvent polarity, the maximum absorption band undergoes a bathochromic shift and the fluorescence emission band undergoes a red shift with a decreased intensity [24]. The reason for these is probably because in a polar environment, the charge separated excited state is probably stabilized to a great extent and prefers to relax only via a non-radiative decay pathway [25]. Thus, the photo-physical properties of ICT molecules depend on the molecular structural characters and the environmental factors. The structural characters are of great importance because they are an intrinsic natures, which include the property of chemical components of $\mathrm{D}$ and $\mathrm{A}$, the conjugation length of the $\pi$-bridge and the conformational organization of the molecular frameworks.

\section{THE REGULATION OF CHARGE TRANSPORT PROPERTIES THROUGH STRUCTURAL DESIGN STRATEGIES}

Many research report have investigated the ICT state from the viewpoints of the property of chemical components of $\mathrm{D}$ and $\mathrm{A}$ [26]. However, only a few researches studied the ICT state based on the other structural properties of molecular frameworks such as substitution position, coplanarity and flexibility $[27,28]$. In fact, the properties of ICT compounds are influenced by both the intrinsic nature of D/A components and the relative orientation of the components [29]. Through a rational choice of the D-A units and a flexible change of the molecular geometry structures, the electron redistribution, highest occupied molecular orbit (HOMO)-lowest unoccupied molecular orbit (LUMO) en- ergy gap and absorption and emission properties [30,31] of the dipolar molecules could be finely controled.

Serevicius and coworkers [32] reported the substitution of 2-phenylanthracene by different aryl groups in the $9^{\text {th }}$ and $10^{\text {th }}$ positions (Fig. 1). Because of the electron donating 2-phenyl group, the $10^{\text {th }}$ position of 2-phenylanthracene is selectively brominated by $N$-bromosuccinimide. The monohalogenated 2-phenylanthracene leads to the synthesis of unsymmetrical 2,9,10-triarylanthracenes. In respect to the anthracene core, 2-phenyl group is twisted with the angles of about $48^{\circ}$ while the aryl groups at the $9^{\text {th }}$ and $10^{\text {th }}$ positions are twisted almost perpendicularly with the angles of about $86.3^{\circ}-89.5^{\circ}$. The introduction of different aryl groups on the anthracene body could cause the increment of the molecular flexibility and the rearrangement of the energy levels. When the energy of optically active triplet state $\left(\mathrm{T}_{n}\right)$ level becomes lower than the lowest singlet state $\left(S_{1}\right)$, the molecule exhibits an efficient intersystem crossing (ISC) and low $\Phi_{\mathrm{F}}$.

Yamato and coworkers [33] reported the synthesis of three asymmetrically substituted 1,3-diphenyl-6,8- $R$-disubstituted pyrenes (Fig. 2), where they employed 1,3-dibromo-7-tert-butylpyrene as the starting material because tert-butyl group could protect the 6- and 8-positions against electrophilic attack since 1-, 3-, 6-, and 8-positions possess the equivalent activity. In respect to the pyrene plane, the phenyl moieties located at the pyrene 1,3-positions are twisted with torsion angles in the range of $45^{\circ}-65^{\circ}$. Among these 1,3-diphenyl-6,8-D/A asymmetrically substituted pyrenes, $7 \mathbf{a}$ in solid-state film exhibits a blue-shifted emission peak comparing to its solution. This is because the bulky electron donor $-\mathrm{NPh}_{2} \mathrm{~F}$ moiety could suppress the aggregation in the solid state and tune the energy gap via the effect of the conformation of the electronic structures. $7 \mathbf{b}$ and $7 \mathbf{c}$ display a red-shifted emission peak compared with in solution because the planar structures tend to form dimers.

Kawai and coworkers [34] also reported the synthesis of three T-shaped $\pi$-conjugated molecules (Fig. 3). Through introducing 2-phenylthieno[3,2-b]thiophene, 2-phenylthiophene or benzothiophene into the backbone of bis(phenylethynyl)arylene with $N$-methylbenzimidazole junction, the properties of the vertical $\pi$-conjugated molecules are regulated with respect to the electronic and geometrical nature including electron donating capability and quinoid character. The electron donating strength is reduced in the order of 2-phenylthieno[3,2-b]thiophene, 2-phenylthiophene and benzothiophene. Because the lower aromatic resonance energy corresponds to the higher 


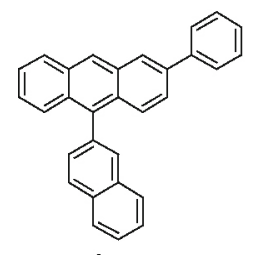

$1 \mathbf{a}$

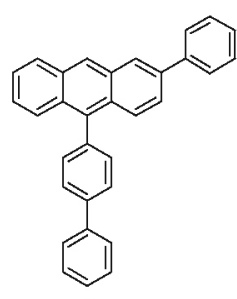

$1 \mathrm{~b}$<smiles></smiles>

2a<smiles>c1ccc(-c2ccc(-c3ccc4c(-c5ccccc5)c5ccccc5c(-c5ccccc5)c4c3)cc2)cc1</smiles>

$2 b$<smiles>c1ccc(-c2ccc(-c3ccc4c(-c5ccc6ccccc6c5)c5ccccc5c(-c5ccc(-c6ccccc6)cc5)c4c3)cc2)cc1</smiles><smiles>c1ccc(-c2ccc3c(-c4ccc5ccccc5c4)c4ccccc4c(-c4cccc5c4ccc4cc6ccccc6cc45)c3c2)cc1</smiles>

$4 a$

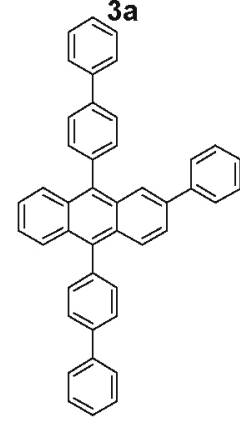

$3 b$<smiles>c1ccc(-c2ccc3c(-c4ccccc4)c4ccccc4c(-c4ccc(-n5c6ccccc6c6ccccc65)cc4)c3c2)cc1</smiles><smiles>c1ccc(-c2ccc(-c3c4ccccc4c(-c4ccc(-n5c6ccccc6c6ccccc65)cc4)c4cc(-c5ccccc5)ccc34)cc2)cc1</smiles>

$5 b$<smiles></smiles><smiles>CCOc1ccc(-c2c3ccccc3c(-c3ccc(-c4ccccc4)cc3)c3ccc(-c4ccccc4)cc23)cc1</smiles>

6b

Figure 1 The non-symmetric 2,9,10-triarylanthracenes.<smiles>Fc1ccc(N(c2ccc(F)cc2)c2cc(N(c3ccc(F)cc3)c3ccc(F)cc3)c3ccc4c(-c5ccccc5)cc(-c5ccccc5)c5ccc2c3c54)cc1</smiles>

$7 a$

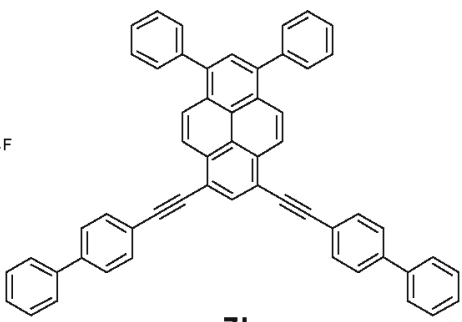

$7 b$<smiles>N#Cc1cc(N)c2ccc3c(-c4ccccc4)cc(-c4ccccc4)c4ccc1c2c34</smiles>

$7 c$

Figure 2 Three asymmetrically substituted 1,3-diphenyl-6,8-R-disubstituted pyrenes.

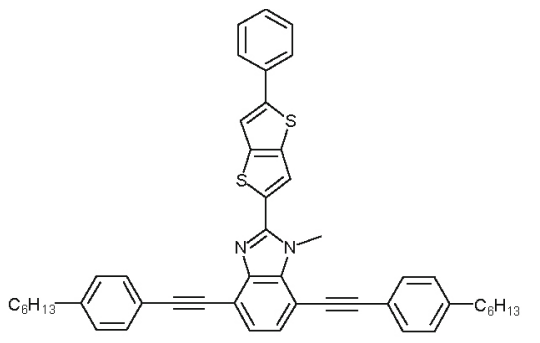

$8 \mathbf{a}$

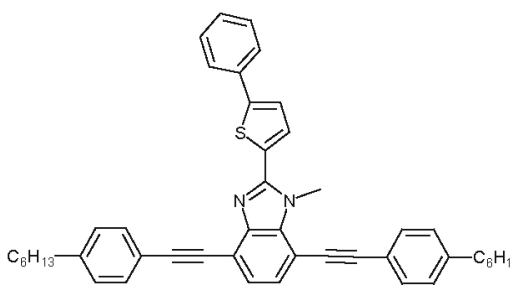

$8 b$<smiles>Cc1ccc(C#Cc2ccc(C#Cc3ccc(C)cc3)c3c2nc(-c2cc4ccccc4s2)n3C)cc1</smiles>

$8 \mathrm{c}$

Figure 3 Three T-shaped cross-conjugated benzimidazole derivatives.

quinoid property, the degree of quinoid character is also decreased at the same order. Since the quinoid nature could effectively suppress the TICT emission and lead to a planar ICT state with an enhanced emission intensity, it could modulate the molecular geometry in the excited state. Thus, the remarkable flexibility of the molecular backbone structure could effectively regulate the ICT properties.

Thus, through the change of the dihedral angles between the D and A ring planes, the alteration of the ICT molecular configuration (linear or nonlinear) and the substituted pattern (symmetrically or asymmetrically), the electron redistribution and the HOMO-LUMO energy level could be tuned, and then the absorption and emission properties 
could be altered.

\section{THE DESIGN AND APPLICATION OF PHOTOELECTRIC ACTIVE MATERIALS BASED ON ICT MOLECULES}

The various D/A moieties, different linkages of ICT molecules, and the conformational organization of the molecular frameworks greatly affect the ICT process, and decide their photoelectric properties. Through rational structural design strategy, desired properties could be obtained and the functional molecular systems including two-photon absorption chromophores, organic photovoltaics and organic light-emitting diodes could be developed.

\section{Two-photon absorption chromophores}

ICT molecules with high hyperpolarizabilities are employed as second- or third-order nonlinear optical (NLO) chromophores. Two-photon absorption (2PA) is an important third-order nonlinear optical effect with wide applications in microscopy, microfabrication, three-dimensional data storage, optical power limiting, up-converted lasing, photodynamic therapy, and for the localized release of bio-active species [35]. There are several strategies to design novel organic molecules with large 2PA cross sections [36]. Usually, increasing the extent of ICT and the enlargement of the conjugation and the enhancement of the coplanarity would result in a large increase of $2 \mathrm{PA}$ cross sections and also a shift of the two-photon absorption peak to longer wavelength [37].

Pyrazine is an electron-poor group while 4-diphenylamino-phenyl unit is an electron-rich group. The integration of two units into one molecule could lead to two-photon absorption chromophores. Following this idea, our group has synthesized three novel 2PA materials through the combination of pyrazine species and 4-diphenylamino-phenyl unit (Fig. 4) [38]. The change of the substituents on the pyrazine ring from phenylene, to dimethylphenylene, to 9,10-dioxo-9,10-dihydro-anthracenyl moiety causes an obvious distinction in 2PA cross section. More interestingly, the protonation of pyrazine units leads to a switch from 2PA to saturated absorption (SA) due to the decrease of the energy gap between the HOMO and the LUMO levels.

Employing 4-diphenylamino-phenyl unit as the electron-rich building block, Wong and co-workers [39] designed and synthesized two D- $\pi$-A type molecules with the electron-poor unit phenylaldehyde or (Z)-4-benzylidene-2-methyloxazol-5(4H)-one (Fig. 5). The maximum 2PA cross sections are $160 \mathrm{GM}$ and $250 \mathrm{GM}$ for 10a and 10b, respectively. The solvent polarity does have some effect on the 2PA strength and the 2PA strength decreases in strongly polar solvent. The possible reason could be that in polar solvent the molecular configurations have a large torsion angle between the D-A planes, which segment the $\pi$-electron coherence into shorter chains, then resulting in a decrease in the 2PA strength.

As an electron acceptor, isoxazolones exhibit high nonlinearities when linked to different electron-donating units. Yang and coworkers [40] designed and synthesized four D-A molecules based on isoxazolone and $N, N$-dimethylaniline or carbazole units. In compounds $\mathbf{1 1 b}$ and 11d (Fig. 6), the dihedral angle between the two benzene rings linked by the ethylenic linkage bond is very small, suggesting an extended $\pi$-conjugated system. In compound 11a, the dihedral angle between the heterocyclic ring plane and the benzene plane that are connected by alkene is also very small, providing a good chance for electron transfer. The nonlinear absorption coefficients for compound 11a, 11c and $11 \mathrm{~d}$ are $8.0 \times 10^{-12}, 1.2 \times 10^{-11}$ and $3.0 \times 10^{-12} \mathrm{~m} \mathrm{~W}^{-1}$, respectively.

The pyrrolo[3,2-b]pyrrole ring is not only an efficient linker allowing the conjugation of peripheral benzene rings, but also an electron donor. Gryko and co-workers [41] designed and synthesized two D-D-A structures using pyrrolo $[3,2-b]$ pyrrole as the first electron $\mathrm{D}$, methoxy or
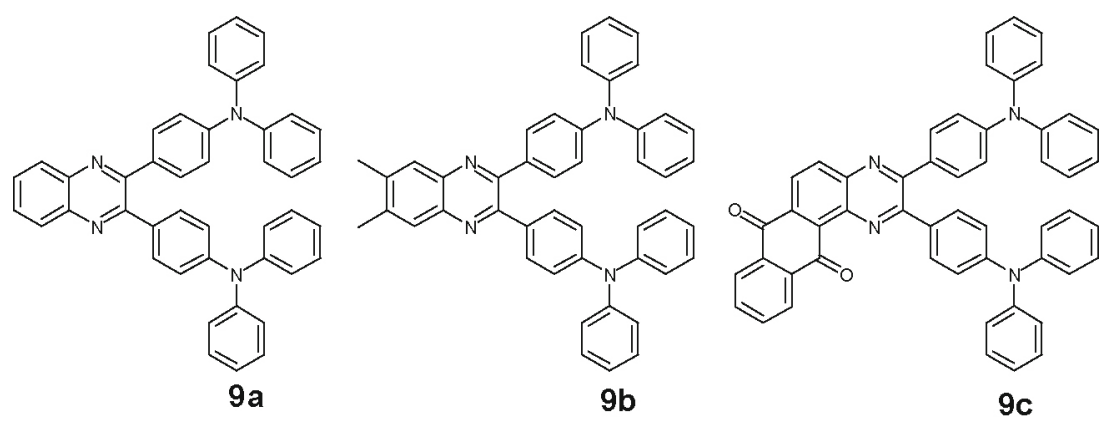

Figure 4 The structures of 4-diphenylamino-phenyl substituted pyrazine. 

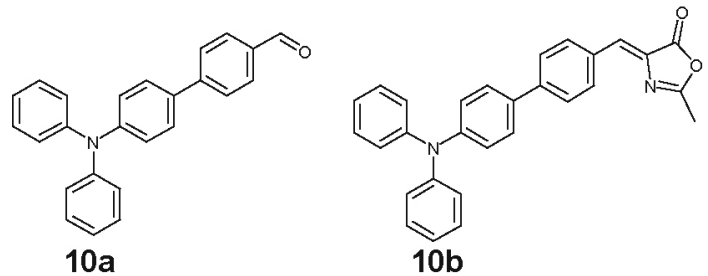

Figure 5 The structures of $10 \mathrm{a}$ and $10 \mathrm{~b}$.

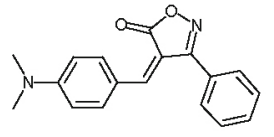

$11 \mathrm{a}$

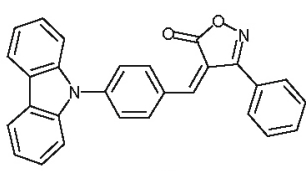

$11 \mathrm{c}$

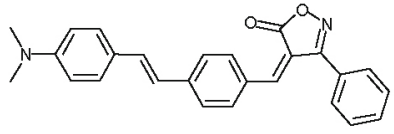

$11 b$

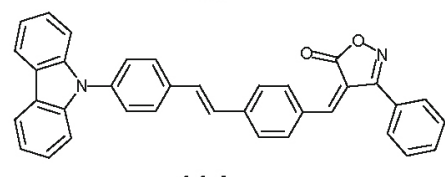

$11 d$
Figure 6 The structures of $11 a-d$.

dialkylamino groups as the second electron donor, and the cyano group as electron A (Fig. 7). In this case, 2PA cross sections increase with the increased polarity. The $2 \mathrm{PA}$ cross sections of compounds $\mathbf{1 2} \mathbf{a}$ and $\mathbf{1 2} \mathbf{b}$ give the maximum values of 222 GM and 340 GM, respectively.

\section{Organic photovoltaics}

ICT structures can induce strong and broad absorption in the visible region, low LUMO and HOMO energy levels and good electron transport ability. Zhan and coworkers [42] designed and synthesized ICT compound 13a (Fig. 8) as the electron A used in bulk-heterojunction ( $\mathrm{BHJ}$ ) polymer solar cells (PSCs), which incorporates a seven-ring fused core (indacenodithieno $[3,2-b]$ thiophene) playing as the $\mathrm{D}$

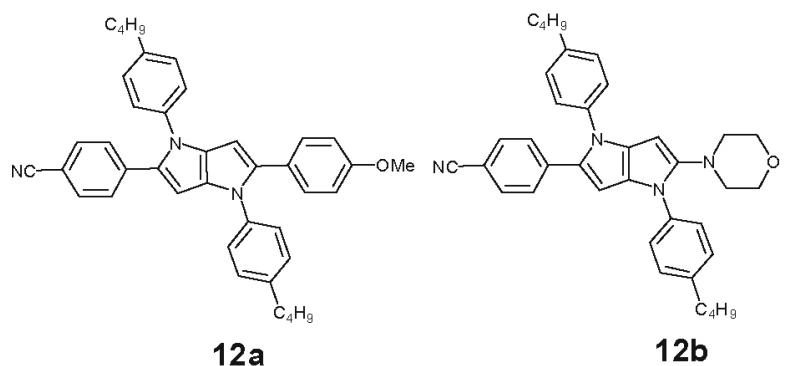

Figure 7 The structures of $\mathbf{1 2} \mathbf{a}$ and $\mathbf{b}$.

part and INCN (2-(3-oxo-2,3-dihydroinden-1-ylidene)malononitrile) as the A part. The extended conjugation in fused rings is beneficial to forming effective interchain $\pi-\pi$ overlaps and enhancing intermolecular charge transport. The introduction of four rigid 4-hexylphenyl substituents onto the fused rings can restrict the molecular planarity and phase separation in $\mathrm{BHJ}$ blend films. The power conversion efficiency (PCE) of $6.80 \%$ for compound $\mathbf{1 3 a}$ is obtained with compound $\mathbf{1 3 b}$ as $\mathrm{D}$ polymers.

Different design strategies for perylene diimide (PDI) based photoactive materials in $\mathrm{BHJ}$ devices have been proposed. Small molecules with D-A-D structures exhibit promising photovoltaic performances together with different D materials such as P3HT or thiophene based oligomers. Kozma and co-workers [43] designed and synthesized two PDI molecules using spirobifluorene groups as D donor substituents, which are linked directly to PDI or through a bithiophene linker (Fig. 9). These molecules exhibit significant twist of the PDI core and the spirobifluorene unit, which can suppress the tendency of PDI to form intermolecular aggregates, and thus the exciton traps are reduced. The optimized efficiency of $1.32 \%$ is obtained

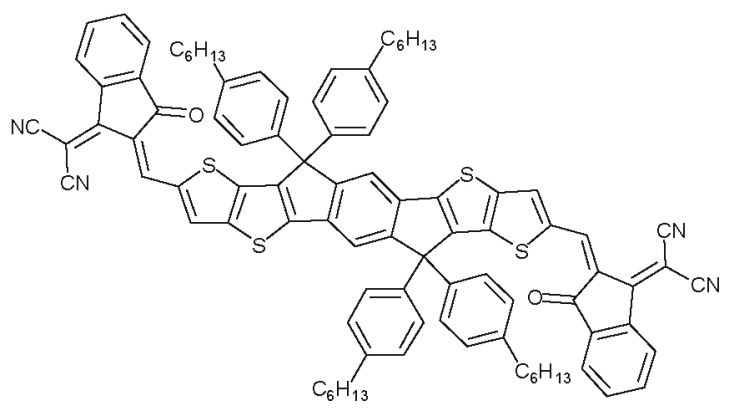

13 a

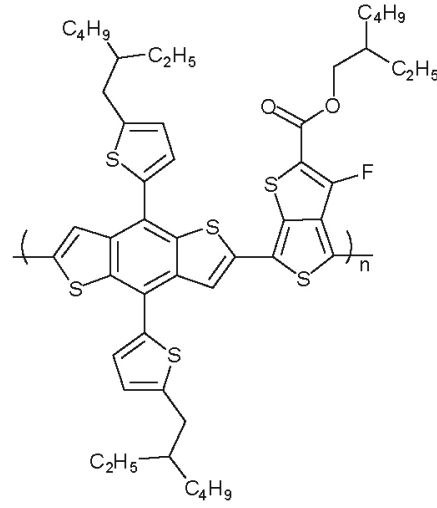

$13 \mathrm{~b}$

Figure 8 The structures of $13 \mathbf{a}$ and $\mathbf{b}$. 

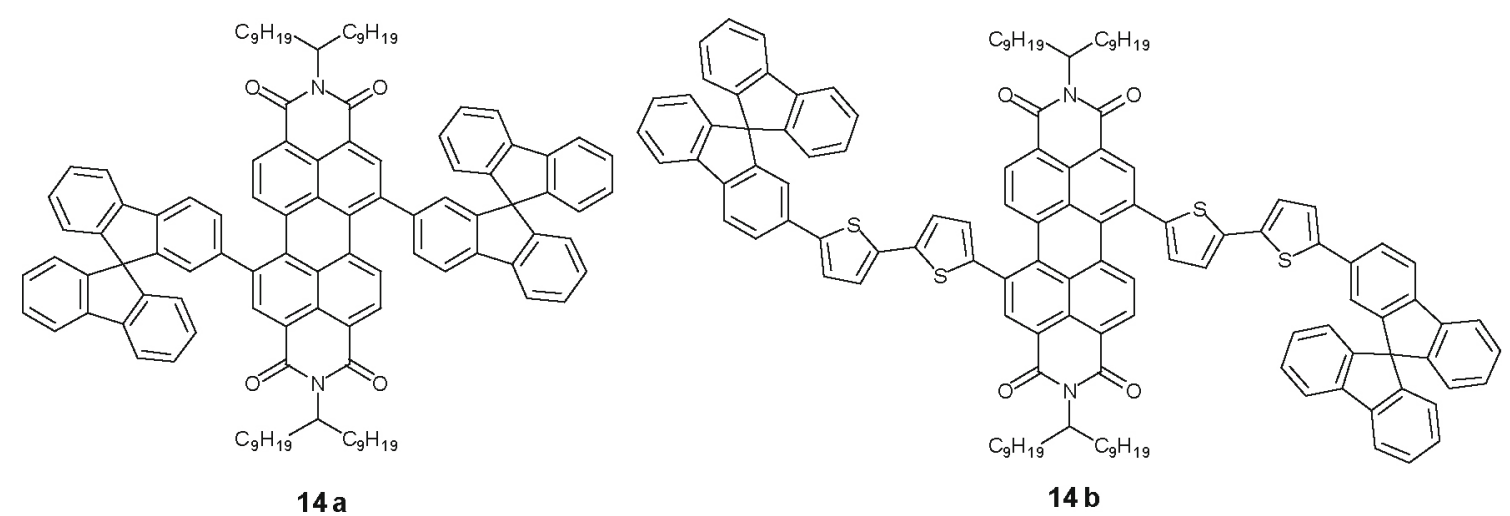

Figure 9 The chemical structures of $\mathbf{1 4 a}$ and $\mathbf{b}$.

for compound 14a.

The PDI derivatives with $\mathrm{D}-\pi$-A structures are also reported in the fabrication of $\mathrm{BHJ}$ devices. Li and co-workers [44] have designed and synthesized novel mono-bay functionalized PDI dyes by introducing strong electron donor anthraquinone (Fig. 10). The 2 -anthraquinone-substituted perylene diimide (compound 15a) undergoes a phototriggered intramolecular cyclization to form anthraquinonoperylene diimide (compound $\mathbf{1 5 b}$ ), thus decreasing the dihedral angles between PDI core and anthraquinone plane. After cyclization, the solubility is decreased and the fluorescent intensity is significantly quenched. The PCE is decreased from $0.39 \%$ to $0.16 \%$.

\section{Organic light-emitting diodes}

D-A type organic molecules have been used as effective alternatives to achieve high efficiency in OLEDs without using heavy atoms containing phosphorescent emitters [45]. The design of a bipolar molecule with a large dihedral angle between a $N$-D and a phenyl ring substituted with elec-

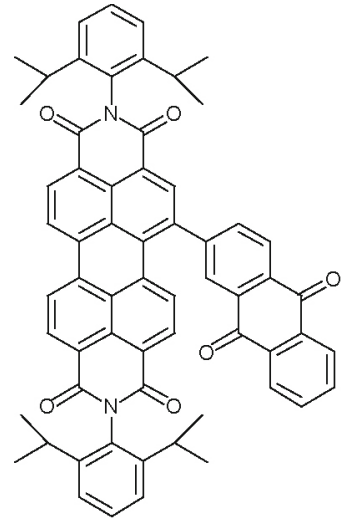

15 a

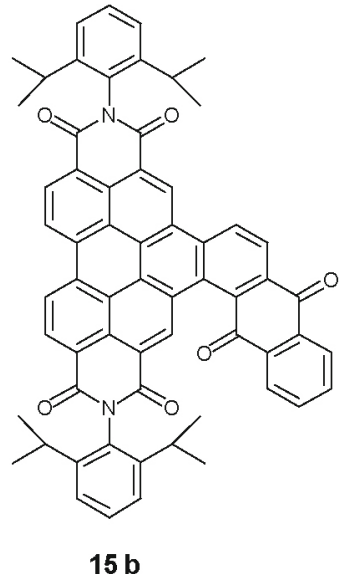

$15 \mathrm{~b}$
Figure 10 The molecular structures of $\mathbf{1 5 a}$ and $\mathbf{1 5 b}$. tron-withdrawing groups is a good strategy to achieve thermally activated delayed fluorescence (TADF) emitters [46-48]. Adachi and coworkers [49] have designed and synthesized some D-A structures and efficient TADF has been characterized for a di-tert-butylcarbazole substituted diphenylsulfone and diphenylamino-phenyl/bis (4-biphenyl)amino-phenyl / di-tert-butylcarbazole-phenyl substituted anthraquinone (Fig. 11) [50]. These molecules have a small energy difference $\left(\Delta E_{\mathrm{ST}}\right)$ between the lowest singlet state $\left(\mathrm{S}_{1}\right)$ and the lowest triplet state $\left(\mathrm{T}_{1}\right)$, thus reverse ISC can take place even in pure aromatic organic compounds containing no heavy metals. The maximum external EL quantum efficiencies (EQE) for 16a, 16b, 16c and $\mathbf{1 6 d}$ are $9.9 \%, 12.5 \%, 9.0 \%$ and $9.0 \%$, respectively.

Our group has also utilized D-A strategy to obtain high efficiency in OLED devices. Dicyano-substituted pyrazine and pyrido[2,3-b]pyrazine moieties are employed as electron-withdrawing groups and diphenylamino-phenyl group is used as electron-donating group (Fig. 12) [51]. Compound $17 \mathbf{a}$ and $17 \mathbf{b}$ show maximum EQE of $4.01 \%$ and $7.37 \%$, respectively.

\section{CONCLUSIONS}

Designing novel ICT compounds with structural and functional diversity and tailorability is a fascinating field due to their wide applications in optics, electronics, and optoelectronics. This review summarized the recent progress on the synthesis, properties and functionalization of ICT compounds. It should be pointed out that, the structural design is the core issue, which includes the chemical components of $\mathrm{D}$ and $\mathrm{A}$, the substitution position, the coplanarity and flexibility of the molecular framework. Through the subtle modification of the structural factors, the ICT properties could be finely tuned, and the desired functions can be achieved. Specifically, for two-photon absorption chromophores, the improvement of extended $\pi$-conjugation 
<smiles>CC(C)(C)c1ccc2c(c1)c1cc(C(C)(C)C)ccc1n2-c1ccc(S(=O)(=O)c2ccc(-n3c4ccc(C(C)(C)C)cc4c4cc(C(C)(C)C)ccc43)cc2)cc1</smiles>

$16 a$<smiles>O=C1c2ccc(-c3ccc(N(c4ccc(-c5ccccc5)cc4)c4ccc(-c5ccccc5)cc4)cc3)cc2C(=O)c2ccc(-c3ccc(N(c4ccc(-c5ccccc5)cc4)c4ccc(-c5ccccc5)cc4)cc3)cc21</smiles><smiles>O=C1c2ccc(-c3ccc(N(c4ccccc4)c4ccccc4)cc3)cc2C(=O)c2ccc(-c3ccc(N(c4ccccc4)c4ccccc4)cc3)cc21</smiles>

$16 \mathrm{~b}$

Figure 11 The molecular structures of $\mathbf{1 6 a}-\mathbf{d}$.<smiles>N#Cc1nc(-c2ccc(N(c3ccccc3)c3ccccc3)cc2)c(-c2ccc(N(c3ccccc3)c3ccccc3)cc2)nc1C#N</smiles>

$17 a$<smiles>c1ccc(N(c2ccccc2)c2ccc(-c3nc4cccnc4nc3-c3ccc(N(c4ccccc4)c4ccccc4)cc3)cc2)cc1</smiles>

$17 \mathrm{~b}$
Figure 12 The molecular structures of $17 \mathbf{a}$ and $\mathbf{b}$.

and coplanarity could increase the 2PA strength. For organic photovoltaics, the planarity and self-aggregation should be restricted to ensure a proper phase-separation. For organic light-emitting diodes, large dihedral angle between $\mathrm{D}$ and $\mathrm{A}$ ring plane facilitates the formation of TADF and a high EQE. Although great achievements have been made in this field, many challenges are remained. Firstly, the exploration of novel chemical reactions for the construction of ICT molecules with unique structures should be conducted. Secondly, the understanding of the structure-function relationship should be in new depth. Thirdly, the new theoretical method of ICT molecules for predicting the preferred geometries and optical and electronic properties should be developed. We believe that the exploration of structure-function relationship among ICT compounds will provide a rich guideline for the construction of photoelectric active materials.

Received 13 December 2016; accepted 26 December 2016; published online 22 February 2017

1 Li C, Li M, Li Y, et al. New anisopleural spindle-like nonlinear optic (NLO) chromophores with a D-D'- $\pi-A^{\prime}-A$ or $D-A^{\prime}-\pi-D^{\prime}-A$ structure: interesting optical behavior and DFT calculation results. J Mater Chem C, 2016, 4: 8392-8398

2 Bredas JL, Durrant JR. Organic photovoltaics. Acc Chem Res, 2009, 42: $1689-1690$

3 Wang C, Okabe T, Long G, et al. A novel D- $\pi$-A small molecule with $\mathrm{N}$-heteroacene as acceptor moiety for photovoltaic application. Dyes Pigments, 2015, 122: 231-237

4 Lin Y, Li Y, Zhan X. Small molecule semiconductors for high-efficiency organic photovoltaics. Chem Soc Rev, 2012, 41: 4245-4272

5 Liu F, Zhou Z, Zhang C, et al. A thieno[3,4-b]thiophene-based non-fullerene electron acceptor for high-performance bulk-heterojunction organic solar cells. J Am Chem Soc, 2016, 138: 15523-15526

6 Yang Y, Zhang ZG, Bin H, et al. Side-chain isomerization on 
an n-type organic semiconductor ITIC acceptor makes $11.77 \%$ high efficiency polymer solar cells. J Am Chem Soc, 2016, 138: 15011-15018

7 Wang JL, Liu KK, Yan J, et al. Series of multifluorine substituted oligomers for organic solar cells with efficiency over $9 \%$ and fill factor of 0.77 by combination thermal and solvent vapor annealing. J Am Chem Soc, 2016, 138: 7687-7697

8 Lin Y, Zhao F, He Q, et al. High-performance electron acceptor with thienyl side chains for organic photovoltaics. J Am Chem Soc, 2016, 138: 4955-4961

9 Xie G, Chen D, Li X, et al. Polarity-tunable host materials and their applications in thermally activated delayed fluorescence organic light-emitting diodes. ACS Appl Mater Interfaces, 2016, 8: 27920-27930

10 Wang C, Yamashita M, Hu B, et al. Synthesis, characterization, and memory performance of two phenazine/triphenylamine-based organic small molecules through donor-acceptor design. Asian Org Chem, 2015, 4: 646-651

11 Wang C, Hu B, Wang J, et al. Rewritable multilevel memory performance of a tetraazatetracene donor-acceptor derivative with good endurance. Chem Asian J, 2015, 10: 116-119

12 Wang C, Gu P, Hu B, et al. Recent progress in organic resistance memory with small molecules and inorganic-organic hybrid polymers as active elements. J Mater Chem C, 2015, 3: 10055-10065

13 Wang C, Wang J, Li PZ, et al. Synthesis, characterization, and non-volatile memory device application of an $\mathrm{N}$-substituted heteroacene. Chem Asian J, 2014, 9: 779-783

14 Li G, Zheng K, Wang C, et al. Synthesis and nonvolatile memory behaviors of dioxatetraazapentacene derivatives. ACS Appl Mater Interfaces, 2013, 5: 6458-6462

15 Li J, Zhang Q. Linearly fused azaacenes: novel approaches and new applications beyond field-effect transistors (FETs). ACS Appl Mater Interfaces, 2015, 7: 28049-28062

16 Gu PY, Zhang J, Long G, et al. Solution-processable thiadiazoloquinoxaline-based donor-acceptor small molecules for thin-film transistors. J Mater Chem C, 2016, 4: 3809-3814

17 Yang Y, Wang H, Liu F, et al. The synthesis of new double-donor chromophores with excellent electro-optic activity by introducing modified bridges. Phys Chem Chem Phys, 2015, 17: 5776-5784

18 Aydemir M, Haykır G, Türksoy F, et al. Synthesis and investigation of intra-molecular charge transfer state properties of novel donor-acceptor-donor pyridine derivatives: the effects of temperature and environment on molecular configurations and the origin of delayed fluorescence. Phys Chem Chem Phys, 2015, 17: 25572-25582

19 Li Y, Liu T, Liu H, et al. Self-assembly of intramolecular chargetransfer compounds into functional molecular systems. Acc Chem Res, 2014, 47: 1186-1198

20 Weigel W, Rettig W, Dekhtyar M, et al. Dual fluorescence of phenyl and biphenyl substituted pyrene derivatives. J Phys Chem A, 2003, 107: 5941-5947

21 Siemiarczuk A, Grabowski ZR, Krówczyński A, et al. Two emitting states of excited p-(9-anthryl)-n,n-dimethylaniline derivatives in polar solvents. Chem Phys Lett, 1977, 51: 315-320

22 Grabowski ZR, Rotkiewicz K, Rettig W. Structural changes accompanying intramolecular electron transfer: focus on twisted intramolecular charge-transfer states and structures. Chem Rev, 2003, 103: 3899-4032

23 Zachariasse KA. Comment on "Pseudo-Jahn-Teller and TICT-models: a photophysical comparison of meta-and para-DMABN derivatives" [Chem. Phys. Lett. 305 (1999) 8]. Chem Phys Lett, 2000, 320: 8-13
24 Grozema FC, Swart M, Zijlstra RWJ, et al. QM/MM study of the role of the solvent in the formation of the charge separated excited state in 9,9'-bianthryl. J Am Chem Soc, 2005, 127: 11019-11028

25 Balamurugan D, Aquino AJA, de Dios F, et al. Multiscale simulation of the ground and photo-induced charge-separated states of a molecular triad in polar organic solvent: exploring the conformations, fluctuations, and free energy landscapes. J Phys Chem B, 2013, 117: 12065-12075

26 Moreno-Yruela C, Garín J, Orduna J, et al. D- $\pi-A$ compounds with tunable intramolecular charge transfer achieved by incorporation of butenolide nitriles as acceptor moieties. J Org Chem, 2015, 80: $12115-12128$

27 Maus M, Rettig W, Bonafoux D, et al. Photoinduced intramolecular charge transfer in a series of differently twisted donor-acceptor biphenyls as revealed by fluorescence. J Phys Chem A, 1999, 103: 3388-3401

28 Maus M, Rettig W. The excited state equilibrium between two rotational conformers of a sterically restricted donor-acceptor biphenyl as characterized by global fluorescence decay analysis. J Phys Chem A, 2002, 106: 2104-2111

29 Felouat A, D'Aléo A, Charaf-Eddin A, et al. Tuning the direction of intramolecular charge transfer and the nature of the fluorescent state in a T-shaped molecular dyad. J Phys Chem A, 2015, 119: 6283-6295

30 Novakova V, Hladík P, Filandrová T, et al. Structural factors influencing the intramolecular charge transfer and photoinduced electron transfer in tetrapyrazinoporphyrazines. Phys Chem Chem Phys, 2014, 16: 5440-5446

31 Mishra R, Lim JM, Son M, et al. Tuning the electronic nature of mono-bay alkynyl-phenyl-substituted perylene bisimides: synthesis, structure, and photophysical properties. Chem Eur J, 2014, 20: 5776-5786

32 Serevičius T, Adomėnas $\mathrm{P}$, Adomėnienė $\mathrm{O}$, et al. Impact of nonsymmetric 2,9,10-aryl substitution on charge transport and optical properties of anthracene derivatives. Dyes Pigments, 2015, 122: 147-159

33 Feng X, Tomiyasu H, Hu JY, et al. Regioselective substitution at the 1,3- and 6,8-positions of pyrene for the construction of small dipolar molecules. J Org Chem, 2015, 80: 10973-10978

34 Inouchi T, Nakashima T, Kawai T. Charge transfer emission of $T$-shaped $\pi$-conjugated molecules: impact of quinoid character on the excited state properties. J Phys Chem A, 2014, 118: 2591-2598

35 Pawlicki M, Collins HA, Denning RG, et al. Two-photon absorption and the design of two-photon dyes. Angew Chem Int Ed, 2009, 48: 3244-3266

36 Albota M, Beljonne D, Bredas JL, et al. Design of organic molecules with large two-photon absorption cross sections. Science, 1998, 281: 1653-1656

37 He GS, Tan LS, Zheng Q, et al. Multiphoton absorbing materials: molecular designs, characterizations, and applications. Chem Rev, 2008, 108: 1245-1330

$38 \mathrm{Xu} \mathrm{L}$, Zhu H, Long G, et al. 4-Diphenylamino-phenyl substituted pyrazine: nonlinear optical switching by protonation. J Mater Chem C, 2015, 3: 9191-9196

39 Zhang Y, Jiang M, Han GC, et al. Solvent effect and two-photon optical properties of triphenylamine-based donor-acceptor fluorophores. J Phys Chem C, 2015, 119: 27630-27638

40 Jiang D, Xue Z, Li Y, et al. Synthesis of donor-acceptor molecules based on isoxazolones for investigation of their nonlinear optical properties. J Mater Chem C, 2013, 1: 5694-5700

41 Orlowski R, Banasiewicz M, Clermont G, et al. Strong solvent dependence of linear and non-linear optical properties of donor-ac- 
ceptor type pyrrolo[3,2-b]pyrroles. Phys Chem Chem Phys, 2015, 17: $23724-23731$

42 Lin Y, Wang J, Zhang ZG, et al. An electron acceptor challenging fullerenes for efficient polymer solar cells. Adv Mater, 2015, 27: $1170-1174$

43 Kozma E, Kotowski D, Catellani M, et al. Design of perylene diimides for organic solar cell: effect of molecular steric hindrance and extended conjugation. Mater Chem Phys, 2015, 163: 152-160

44 Xu L, Liu C, Qin Z, et al. Core expansion of perylenetetracarboxdiimide dyes with anthraquinone units for electron-accepting materials. Eur J Org Chem, 2013, 2013: 300-306

45 Duan L, Qiao J, Sun Y, et al. Strategies to design bipolar small molecules for OLEDs: donor-acceptor structure and non-donoracceptor structure. Adv Mater, 2011, 23: 1137-1144

46 Endo A, Sato K, Yoshimura K, et al. Efficient up-conversion of triplet excitons into a singlet state and its application for organic light emitting diodes. Appl Phys Lett, 2011, 98: 083302

47 Uoyama H, Goushi K, Shizu K, et al. Highly efficient organic light-emitting diodes from delayed fluorescence. Nature, 2012, 492: $234-238$

48 Zhang Q, Li B, Huang S, et al. Efficient blue organic light-emitting diodes employing thermally activated delayed fluorescence. Nat Photon, 2014, 8: 326-332
49 Zhang Q, Li J, Shizu K, et al. Design of efficient thermally activated delayed fluorescence materials for pure blue organic light emitting diodes. J Am Chem Soc, 2012, 134: 14706-14709

50 Zhang Q, Kuwabara H, Potscavage Jr. WJ, et al. Anthraquinonebased intramolecular charge-transfer compounds: computational molecular design, thermally activated delayed fluorescence, and highly efficient red electroluminescence. J Am Chem Soc, 2014, 136: $18070-18081$

51 Xu L, Zhao Y, Long G, et al. Synthesis, structure, physical properties and OLED application of pyrazine-triphenylamine fused conjugated compounds. RSC Adv, 2015, 5: 63080-63086

Acknowledgments This work was supported by AcRF Tier 1 (RG 8/16, RG 133/14 and RG 13/15) from MOE, Singapore, STU Scientific Research Foundation for Talents (NTF15005), STU Youth Research Fund (YR15001) and the Foundation for Young Talents in Higher Education of Guangdong (2015KQNCX042).

Author contributions $\quad \mathrm{Xu} \mathrm{L}$ wrote this manuscript under the guidance of Zhang Q. All authors contributed to the general discussion and article revision.

Conflict of interest The authors declare that they have no conflict of interest.

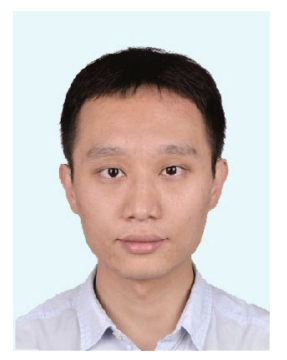

Liang Xu received his BSc degree from the Department of Chemistry, China Agricultural University in 2009, and his PhD degree from the Institute of Chemistry, Chinese Academy of Sciences (ICCAS) in 2014, under the supervision of Prof. Yuliang Li. He did his postdoctoral research at the School of Materials Science and Engineering, Nanyang Technological University (NTU, Singapore), in Prof. Qichun Zhang's group. His research interests are focused on the design, synthesis, characterization and application exploration of intramolecular charge-transfer compounds.

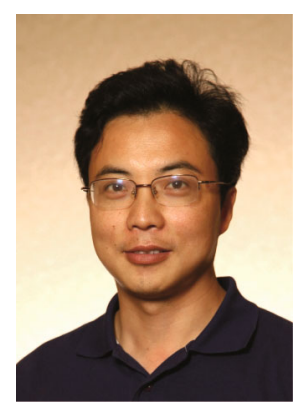

Qichun Zhang obtained his BSc degree at Nanjing University in 1992, MSc degree in physical organic chemistry (Organic Solid Lab) at ICCAS (Prof. Peiji Wu/Daoben Zhu's group) in 1998, MSc degree in organic chemistry (Prof. Fred Wudl's group) at the University of California, Los Angeles (USA), and completed his PhD degree in inorganic chemistry at the University of California Riverside (Prof. Pingyun Feng's group, USA) in 2007. Then, he joined Prof. Kanatzidis' group at Northwestern University as a postdoctoral fellow (Oct. 2007-Dec. 2008). Since Jan. 2009, he joined the School of Materials Science and Engineering at NTU as an assistant professor. On Mar 1st, 2014, he has promoted to associate professor with tenure and on Dec. 1st, 2014, he became an adjunct associate professor at Division of Chemistry and Biological Chemistry, School of Physical and Mathematical Sciences, NTU. Besides these, he also had three-year working experience in Research Institute of Nanjing Chemical Industry Co. (Aug. 1992 - Aug. 1995) and two-year's research experience in ICCAS (Aug. 1998 - Jun 2000). He received TCT fellowship in 2013 and lectureship from National Taiwan University in 2014. Currently, he is an associate editor of $J$ Solid State Chem and the advisory board member of Mater Chem Frontiers. He has published $>220$ papers and 4 patents (H-index: 46).

\section{分子内电荷转移化合物在光电活性材料中的应用进展}

许良 ${ }^{1^{*}}$, 张其春 ${ }^{2,3^{*}}$

摘要 本文综述了分子内电荷转移化合物的结构设计和合成策略, 及其在双光子吸收材料、有机光伏器件和有机发光二极管等领域的应 用进展. 